\title{
Analysis of Clinical Characteristics of 19 Patients with Endophthalmitis Caused by Liver Abscess
}

guangsen liu ( $\sim$ lgs9366@yeah.net)

Moorfields Eye Hospital https://orcid.org/0000-0002-6871-6051

Yue Li

Qindao University Medical College Affiliated Yantai Yuhuangding Hospital

Wei Wang

Qindao University Medical College Affiliated Yantai Yuhuangding Hospital

Lei Gao

Weifang Eye Hospital

\section{Research Article}

Keywords: Endophthalmitis, Liver abscess, Klebsiella pneumonia, Vitrectomy, Intravitreal injections

Posted Date: April 27th, 2021

DOl: https://doi.org/10.21203/rs.3.rs-319989/v1

License: (c) (i) This work is licensed under a Creative Commons Attribution 4.0 International License. Read Full License 


\section{Abstract}

Objective: To analyze the clinical features, treatment, and prognosis of endophthalmitis caused by a liver abscess.

Methods: All cases of endogenous endophthalmitis caused by a liver abscess in our hospital in the past 7 years were analyzed retrospectively. The data collected included age, sex, history of diabetes, initial and final vision, pathogen, course of the disease, treatment, and prognosis.

Results: 21 eyes of 19 patients were complicated with liver abscess. The average age was $55.9 \pm 9.8$ years old, including 10 males (52.6\%) and 9 females (44.4\%), 13 patients complicated with diabetes (71.4\%), 14 patients (66.7\%) first went to the ophthalmology department for diagnosis and treatment and 5 with hepatobiliary surgery (33.3\%). 14 patients had a fever before onset, with an average fever time of 5.8 days. Before treatment, the duration of ocular symptoms was $7.71 \pm 6.68$ days, $5.71 \pm 1.25$ days for patients who go to ophthalmology for diagnosis and treatment for the first time, and $12.2 \pm 3.58$ days for patients who go to other departments. After treatment, the average visual acuity of 21 eyes was 0.013 , and the average bestcorrected visual acuity was 0.79 . In the 21 eyes, vitreous fluid culture was positive in 7 eyes (33.3\%), all of which were Klebsiella pneumonia. Among the 14 patients with fever during hospitalization, 5 cases were positive for blood microbial culture, all of which were Klebsiella pneumonia. After vitrectomy, the average visual acuity was improved by $4.90 \pm 2.47$ letters and that of patients without vitrectomy was- $0.25 \pm 0$.16letters. The visual acuity of patients who underwent postoperative visual was significantly better than that of patients without postoperative visual $(\mathrm{P} \otimes 0.096)$. The visual acuity of patients without vitrectomy was significantly higher than that of patients without vitrectomy ( $\mathrm{P} \otimes 0.01)$. 3 eyes (33.3\%) of 9 eyes in the IVI group were removed because of uncontrolled inflammation, and 1 eye of 12 eyes in the PPV group was removed because of inflammation recurrence.

Conclusion: The prognosis of endogenous endophthalmitis caused by liver abscess is generally poor, but early treatment can save part of the vision. The first visit non-ophthalmology department will delay the early diagnosis of the disease. Diabetes is an important risk factor for endogenous endophthalmitis and poor vision in patients with liver abscess. Klebsiella pneumonia is the main pathogen of intraocular infection. Vitrectomy combined with vitreous injection of antibiotics can improve the prognosis. A systematic and thorough treatment of a liver abscess is of great significance to prevent the recurrence of endophthalmitis in a liver abscess.

\section{Introduction}

Clinically, endogenous endophthalmitis accounts for $2 \sim 15 \%$ of all infectious endophthalmitis ${ }^{[1]}$. In recent years, due to the abuse of antibiotics and hormones and the continuous improvement of the level of rescue and treatment of critically ill patients, the incidence of endogenous endophthalmitis has increased, and the incidence is different in different regions. In western countries, about $10 \%$ of cases of endophthalmitis are attributed to endogenous intraocular infections, and the proportion of endogenous endophthalmitis in Japan is as high as $31 \%$. The risk factors of endogenous endophthalmitis are diabetes, endocarditis, liver abscess, meningitis, major surgery, intravenous medication, oral surgery, intravenous medication, AIDS, immunodeficiency disease, leukopenia, diffuse intravascular coagulation (DIC), among which diabetes is the most common risk factor. The ratio of endophthalmitis caused by a liver abscess in endogenous endophthalmitis is increasing year by year. In the investigation of endogenous endophthalmitis in Korea, $25 \%$ of the primary focus of endogenous endophthalmitis is liver abscess ${ }^{[2]}$. Studies in Taiwan have found that the proportion of septicemia caused by liver abscesses is as high as $52 \%(39 / 74)^{[3]}$. In Asia, especially in China, North Korea, South Korea, Japan, Mongolia, and other East Asian countries, the main focus of endogenous endophthalmitis is liver abscess ${ }^{[4]}$. The incidence of liver abscess is hidden but can be asymptomatic at an early stage. Therefore, some patients did not find themselves suffering from liver abscess before seeing a doctor but went to the ophthalmology department for treatment because of eye discomfort, which puts forward higher requirements for the accurate diagnosis of the disease by ophthalmologists.

\section{Materials And Methods}


General data: 19 cases (21 eyes) of endophthalmitis caused by a liver abscess in our hospital from January 2010 to September 2017 were analyzed retrospectively. There were 10 males and 9 females. The average age was $55.9 \pm 9.8$ years old, 13 cases were complicated with diabetes, 14 cases were first to go to the ophthalmology department, 5 cases were first going to the hepatobiliary surgery, and 14 cases were accompanied with fever before onset. The average time of fever was $5.67 \pm 5.38$ days. The average interval from the onset of eye symptoms to the visit to the ophthalmology department was $7.71 \pm 6.68$ days. The inclusion criteria were as follows: Endophthalmitis was diagnosed by a professional ophthalmologist and the patient suffered from liver abscess, excluding risk factors such as endocarditis, meningitis, major surgery, intravenous medication, oral surgery, intravenous medication, AIDS, immunodeficiency disease, leucopenia, and so on.

\subsection{Examination methods}

All patients underwent detailed ophthalmic examination, including visual acuity, intraocular pressure, slit lamp, fundus, and ocular B-ultrasound, abdominal B-ultrasound diagnosed as liver abscess, cardiac color ultrasound excluded endocarditis, blood routine, urine routine, blood biochemistry, five items of hepatitis $B$, four items before blood transfusion and pulmonary infection. If there were signs of septicemia such as fever, blood was taken for microbial culture and drug sensitivity tests. When performing vitreous injection or vitrectomy, part of the vitreous body is extracted for microbial culture and drug sensitivity.

1.3 All patients were given broad-spectrum antibiotics immediately after the diagnosis was confirmed. Antibiotics are mainly third-generation cephalosporins or broad-spectrum compound antibiotics, and the use of antibiotics is adjusted according to the results of microbial culture and drug sensitivity. Use ciliary paralysis drugs to dilate the pupil and drop antibiotic eye drops. 19 eyes were treated with intravitreal injection of (IVI) antibiotics. The selected antibiotics were $10 \mathrm{mg} / \mathrm{ml}, 0.1 \mathrm{ml}(1 \mathrm{mg})$ imipenem and $10 \mathrm{mg} / \mathrm{ml}, 0.1 \mathrm{ml}(1 \mathrm{mg})$ vancomycin. Among them, 14 eyes were given a single vitreous injection, 3 eyes were given two vitreous injections successively, the interval between two injections was 2, 3, 7 days (the average interval is 4 days). 3 vitreous injections were performed in 2 eyes, the interval between two injections was 2, 12 days and 7, 2 days (the average interval is 5.25 days). The average number of injections was 1.2. Among them, 2 cases (2 eyes)underwent vitrectomy immediately after hospitalization. Vitrectomy was performed in 10 eyes after vitreous injection, and the interval is $1,1,1,1,2,2$, $3,4,9,17$ days, with an average interval of 4.1 days. During a vitrectomy, $1.0 \mathrm{mg}$ vancomycin was added into intraocular perfusion. Subretinal abscess and retinal detachment were found in 7 eyes during vitrectomy, all vitreous bodies, and subretinal empyema was removed. Sensitive antibiotics were given intravenously after vitrectomy, and the treatment plan was adjusted according to the postoperative inflammatory reaction. If there is recurrent inflammation, the vitreous cavity will be injected again, and adjust the vitreous cavity and systemic antibiotics according to the results of microbial culture and drug sensitivity. If the culture result is negative, the therapeutic drug and dose will be the same as before. 9 eyes were treated with IVI combined with systemic antibiotics, of which 3 eyes had a severe inflammatory reaction and underwent evisceration of eye contents. 12 eyes undergoing vitrectomy, 1 eye underwent enucleation of the contents of the eye because the condition was repeated and the inflammation could not be controlled because of the incomplete treatment of the primary focus. 
Table 1

\begin{tabular}{|c|c|c|c|c|c|c|c|c|c|}
\hline $\begin{array}{l}\text { Case } \\
\text { number }\end{array}$ & Gender & age & $\begin{array}{l}\text { Diseased } \\
\text { eye }\end{array}$ & diabetes & fever & $\begin{array}{l}\text { first diagnosis } \\
\text { department }\end{array}$ & $\begin{array}{l}\text { The time interval } \\
\text { from the } \\
\text { occurrence of } \\
\text { eye symptoms } \\
\text { to the visit to the } \\
\text { ophthalmology } \\
\text { department(day) }\end{array}$ & $\begin{array}{l}\text { Location } \\
\text { of liver } \\
\text { abscess }\end{array}$ & $\begin{array}{l}\text { Maximum } \\
\text { diameter } \\
\text { of liver } \\
\text { abscess }\end{array}$ \\
\hline 1 & Female & 59 & OD & 1 & 1 & Ophthalmology & 5 & $\begin{array}{l}\text { The } \\
\text { right } \\
\text { lobe of } \\
\text { the liver }\end{array}$ & $2.5 \mathrm{~cm}$ \\
\hline 2 & Male & 54 & OD & 1 & 2 & Ophthalmology & 2 & $\begin{array}{l}\text { The } \\
\text { right } \\
\text { lobe of } \\
\text { the liver }\end{array}$ & $8.2 \mathrm{~cm}$ \\
\hline 3 & Female & 64 & OS & 1 & 1 & Ophthalmology & 8 & $\begin{array}{l}\text { The } \\
\text { right } \\
\text { lobe of } \\
\text { the liver }\end{array}$ & $5.2 \mathrm{~cm}$ \\
\hline 4 & Female & 60 & OD & 2 & 1 & Ophthalmology & 1 & $\begin{array}{l}\text { The } \\
\text { right } \\
\text { lobe of } \\
\text { the liver }\end{array}$ & $2.8 \mathrm{~cm}$ \\
\hline 5 & Male & 60 & OS & 1 & 1 & Ophthalmology & 5 & $\begin{array}{l}\text { The } \\
\text { right } \\
\text { lobe of } \\
\text { the liver }\end{array}$ & $5.9 \mathrm{~cm}$ \\
\hline 6 & Male & 52 & OS & 1 & 1 & Ophthalmology & 5 & $\begin{array}{l}\text { The } \\
\text { right } \\
\text { lobe of } \\
\text { the liver }\end{array}$ & $3.6 \mathrm{~cm}$ \\
\hline 7 & Male & 59 & os & 2 & 1 & Ophthalmology & 8 & $\begin{array}{l}\text { The } \\
\text { right } \\
\text { lobe of } \\
\text { the liver }\end{array}$ & $11 \mathrm{~cm}$ \\
\hline 8 & Male & 60 & OD & 1 & 1 & Ophthalmology & 3 & $\begin{array}{l}\text { The } \\
\text { right } \\
\text { lobe of } \\
\text { the liver }\end{array}$ & $6.8 \mathrm{~cm}$ \\
\hline 9 & Female & 46 & OS & 1 & 2 & Ophthalmology & 7 & $\begin{array}{l}\text { The } \\
\text { right } \\
\text { lobe of } \\
\text { the liver }\end{array}$ & $3.4 \mathrm{~cm}$ \\
\hline 10 & Male & 50 & OS & 2 & 1 & Ophthalmology & 6 & $\begin{array}{l}\text { The } \\
\text { right } \\
\text { lobe of } \\
\text { the liver }\end{array}$ & $6.5 \mathrm{~cm}$ \\
\hline 11 & Female & 75 & OD & 2 & 2 & Ophthalmology & 5 & $\begin{array}{l}\text { Left lobe } \\
\text { of the } \\
\text { liver }\end{array}$ & $4.6 \mathrm{~cm}$ \\
\hline 12 & Male & 71 & OD & 1 & 1 & $\begin{array}{l}\text { Hepatological } \\
\text { Surgery } \\
\text { Department }\end{array}$ & 10 & $\begin{array}{l}\text { The } \\
\text { right } \\
\text { lobe of } \\
\text { the liver }\end{array}$ & $4.5 \mathrm{~cm}$ \\
\hline
\end{tabular}




\begin{tabular}{|c|c|c|c|c|c|c|c|c|c|}
\hline $\begin{array}{l}\text { Case } \\
\text { number }\end{array}$ & Gender & age & $\begin{array}{l}\text { Diseased } \\
\text { eye }\end{array}$ & diabetes & fever & $\begin{array}{l}\text { first diagnosis } \\
\text { department }\end{array}$ & $\begin{array}{l}\text { The time interval } \\
\text { from the } \\
\text { occurrence of } \\
\text { eye symptoms } \\
\text { to the visit to the } \\
\text { ophthalmology } \\
\text { department(day) }\end{array}$ & $\begin{array}{l}\text { Location } \\
\text { of liver } \\
\text { abscess }\end{array}$ & $\begin{array}{l}\text { Maximum } \\
\text { diameter } \\
\text { of liver } \\
\text { abscess }\end{array}$ \\
\hline 13 & Female & 61 & OS & 1 & 1 & $\begin{array}{l}\text { Hepatological } \\
\text { Surgery } \\
\text { Department }\end{array}$ & 20 & $\begin{array}{l}\text { The } \\
\text { right } \\
\text { lobe of } \\
\text { the liver }\end{array}$ & $3.1 \mathrm{~cm}$ \\
\hline 14 & Male & 42 & os & 2 & 1 & Ophthalmology & 20 & $\begin{array}{l}\text { The } \\
\text { right } \\
\text { lobe of } \\
\text { the liver }\end{array}$ & $3.6 \mathrm{~cm}$ \\
\hline 15 & Female & 44 & OU & 1 & 1 & $\begin{array}{l}\text { Hepatological } \\
\text { Surgery } \\
\text { Department }\end{array}$ & 20 & $\begin{array}{l}\text { The } \\
\text { right } \\
\text { lobe of } \\
\text { the liver }\end{array}$ & $3.2 \mathrm{~cm}$ \\
\hline 16 & Male & 47 & OU & 1 & 1 & $\begin{array}{l}\text { Hepatological } \\
\text { Surgery } \\
\text { Department }\end{array}$ & 1 & $\begin{array}{l}\text { The } \\
\text { right } \\
\text { lobe of } \\
\text { the liver }\end{array}$ & $7.5 \mathrm{~cm}$ \\
\hline 17 & Female & 60 & $O D$ & 2 & 1 & Ophthalmology & 3 & $\begin{array}{l}\text { The } \\
\text { right } \\
\text { lobe of } \\
\text { the liver }\end{array}$ & $2.9 \mathrm{~cm}$ \\
\hline 18 & Female & 61 & os & 1 & 1 & $\begin{array}{l}\text { Hepatological } \\
\text { Surgery } \\
\text { Department }\end{array}$ & 10 & $\begin{array}{l}\text { Left lobe } \\
\text { of the } \\
\text { liver }\end{array}$ & $6.6 \mathrm{~cm}$ \\
\hline 19 & Male & 37 & os & 1 & 2 & Ophthalmology & 2 & $\begin{array}{l}\text { The } \\
\text { right } \\
\text { lobe of } \\
\text { the liver }\end{array}$ & $4.8 \mathrm{~cm}$ \\
\hline
\end{tabular}

\section{Remark}

$\mathrm{OD}=$ right eye, $\mathrm{OS}=$ left eye, $\mathrm{OU}=$ both eyes, 1 in diabetes and fever column means the presence of diabetes and fever, 2 represents no diabetes and fever

\section{Results}

1. The follow-up time ranged from 3 to 12 months, with an average of 6.7 months. The changes in visual acuity and the results of pathogen culture were observed. Taking the last follow-up as the endpoint of judging the curative effect, the bestcorrected visual acuity was measured as the final visual acuity.

2. All 19 patients were diagnosed with liver abscess by abdominal ultrasound. The minimum diameter of the liver abscess was $2.5 \mathrm{~cm}$, and the maximum diameter was $11 \mathrm{~cm}$. The average diameter of the liver abscess was $5.12 \pm 2.23 \mathrm{~cm}$. 14 patients first went to ophthalmology for diagnosis and treatment, and 5 patients first went to hepatobiliary surgery. The average interval of eye discomfort before treatment was $7.71 \pm 6.68$ days. Patients who first went to the ophthalmology department for diagnosis and treatment had an average of $5.71 \pm 1.25$ days of eye discomfort before going to the ophthalmology department, and $12.2 \pm 3.58$ days for patients who first went to the non-ophthalmology departments. Visual acuity decreased in all eyes, no light perception in 9 eyes, light perception in 4 eyes, manual vision in 5 eyes, 
exponential vision in 2 eyes, and 0.25 in 1 eye. Eye pain, conjunctival congestion, and corneal edema were found in all eyes. Empyema in the anterior chamber and vitreous cavity was found in 19 eyes and fundus details were not visible.

3. Vitreous microorganism culture was positive in 7 eyes(7/21,33.3\%), all of which were Klebsiella pneumonia. Liver abscess fluid was obtained from all patients by a percutaneous puncture for microbiological culture, 4 patients were positive and all of them were Klebsiella pneumonia. 14 patients had a fever during hospitalization, and blood samples were taken for microbial culture during fever, 5 cases were positive $\triangle 5 / 14 \otimes 35.7 \% \bigotimes$, all of which were Klebsiella pneumonia. The results of the drug sensitivity test showed that all KP were highly sensitive to most antibiotics except ampicillin.

4. After admission, an emergency intravitreal injection of antibiotics was performed in 19 eyes and vitrectomy in 2 eyes, vitrectomy was performed in 10 eyes after intravitreous injection. None of the eyes which underwent emergency vitrectomy were given intravitreal injection of antibiotics after vitrectomy. In 9 eyes treated with vitreous injection alone, the final Table 2

\begin{tabular}{|c|c|c|c|c|c|c|c|c|c|c|c|c|c|c|c|c|c|c|c|}
\hline Case number & 1 & 2 & 3 & 4 & 5 & 6 & 7 & 8 & 9 & 10 & 11 & 12 & 13 & 14 & 15 & 16 & 17 & 18 & 19 \\
\hline $\begin{array}{l}\text { Blood } \\
\text { microbial } \\
\text { culture }\end{array}$ & $\mathrm{KP}$ & $\mathrm{KP}$ & - & - & - & - & - & $\mathrm{KP}$ & $\mathrm{KP}$ & - & - & - & - & - & - & - & - & - & $\mathrm{KP}$ \\
\hline $\begin{array}{l}\text { Microbial } \\
\text { culture of liver } \\
\text { abscess fluid }\end{array}$ & - & $\mathrm{KP}$ & - & - & - & - & - & - & - & - & - & - & KP & - & - & - & - & - & $\mathrm{KP}$ \\
\hline $\begin{array}{l}\text { Vitreous fluid } \\
\text { microbial } \\
\text { culture }\end{array}$ & $\mathrm{KP}$ & $\mathrm{KP}$ & - & - & - & - & - & $\mathrm{KP}$ & $\mathrm{KP}$ & - & - & - & - & $\mathrm{KP}$ & - & $\mathrm{KP}$ & - & - & $\mathrm{KP}$ \\
\hline
\end{tabular}

Visual acuity was 0.4 in 1 eye, light perception in 1 eye, no light perception in 4 eyes, and evisceration of ocular contents in 3 eyes with panophthalmitis due to uncontrolled inflammation. In 12 eyes after vitrectomy, the final visual acuity was 0.4 in 1 eye, 0.15 in 2 eyes, 0.25 in 1 eye, 0.3 in 1 eye, light perception in 3 eyes, no light perception in 2 eyes, and evisceration of ocular contents in 1 eye with panophthalmitis caused by repeated inflammation. After simple vitreous injection, the visual acuity was improved in 1 eye, unchanged in 7 eyes, and decreased in 1 eye. After vitrectomy, the visual acuity was improved in 6 eyes, unchanged in 2 eyes, and decreased in 4 eyes. 
Table 3

\begin{tabular}{|c|c|c|c|c|c|c|c|c|c|}
\hline $\begin{array}{l}\text { Case } \\
\text { number }\end{array}$ & $\begin{array}{l}\text { Diseased } \\
\text { eye }\end{array}$ & $\begin{array}{l}\text { Initial } \\
\text { vision }\end{array}$ & $\begin{array}{l}\text { Final } \\
\text { vision }\end{array}$ & $\begin{array}{l}\text { Vision } \\
\text { improvement }\end{array}$ & IVI & PPV & $\begin{array}{l}\text { the interval } \\
\text { between IVI and } \\
\text { PPV (day) }\end{array}$ & $\begin{array}{l}\text { Subretinal } \\
\text { empyema }\end{array}$ & $\begin{array}{l}\text { the } \\
\text { evisceration of } \\
\text { ocular contents }\end{array}$ \\
\hline 1 & OD & 0 & 0 & 0 & 1 & 2 & - & 3 & 1 \\
\hline 2 & OD & 0 & 0 & 0 & 1 & 2 & - & 3 & 2 \\
\hline 3 & os & 0.001 & 0 & -0.001 & 1 & 1 & 2 & 2 & 2 \\
\hline 4 & OD & 0 & 0 & 0 & 1 & 1 & 1 & 2 & 2 \\
\hline 5 & os & 0 & 0 & 0 & 1 & 1 & 3 & 2 & 2 \\
\hline 6 & os & 0 & 0.25 & 0.25 & 1 & 1 & 4 & 1 & 2 \\
\hline 7 & os & 0.01 & 0.3 & 0.29 & 1 & 1 & 9 & 2 & 2 \\
\hline 8 & OD & 0.001 & 0 & -0.001 & 1 & 2 & - & 3 & 1 \\
\hline 9 & os & 0 & 0 & 0 & 1 & 2 & - & 3 & 1 \\
\hline 10 & os & 0.001 & 0.01 & 0.009 & 2 & 1 & $\begin{array}{l}\text { Emergency } \\
\text { surgery }\end{array}$ & 1 & 2 \\
\hline 11 & OD & 0 & 0 & 0 & 1 & 2 & - & 3 & 2 \\
\hline 12 & OD & 0 & 0 & 0 & 1 & 1 & 2 & 1 & 2 \\
\hline 13 & os & 0 & 0 & 0 & 1 & 2 & - & 3 & 2 \\
\hline 14 & os & 0 & 0 & 0 & 1 & 2 & - & 3 & 2 \\
\hline 15 & OD & 0.001 & 0.4 & 0.399 & 1 & 1 & 17 & 1 & 2 \\
\hline 15 & os & 0.25 & 0.4 & 0.15 & 1 & 2 & - & 3 & 2 \\
\hline 16 & OD & 0.001 & 0 & -0.001 & 1 & 1 & 1 & 1 & 1 \\
\hline 16 & os & 0.01 & 0.15 & 0.14 & 1 & 1 & 1 & 2 & 2 \\
\hline 17 & OD & 0 & 0 & 0 & 1 & 2 & - & 3 & 2 \\
\hline 18 & os & 0 & 0.15 & 0.15 & 1 & 1 & 1 & 1 & 2 \\
\hline 19 & os & 0 & 0 & 0 & 2 & 1 & $\begin{array}{l}\text { Emergency } \\
\text { surgery }\end{array}$ & 1 & 2 \\
\hline \multicolumn{10}{|c|}{$\begin{array}{l}\text { Remark: Visual acuity: } 0=\text { light perception and no light perception; } 0.001=\text { hand movements; } 0.01=\text { count fingers; IVI = } \\
\text { intravitreal injection, PPV = pars plana vitrectomy, } 1 \text { means IVI or PPV, } 2 \text { means no IVI or PPV; subretinal empyema: } 1 \\
\text { indicates the presence of subretinal empyema, } 2 \text { indicates no subretinal empyema, } 3 \text { means the situation is unknown, eye } \\
\text { content surgery: } 1 \text { = operated evisceration of ocular contents, } 2=\text { no operated evisceration of ocular contents }\end{array}$} \\
\hline
\end{tabular}

\section{Discussion}

Liver abscess is the most common risk factor for endogenous endophthalmitis in East Asian countries including China. A retrospective analysis of 19 related cases was conducted, of which 14 cases (14/19,73.7\%)had febrile symptoms before onset, it is suggested that there is septicemia and the bacteria have spread into the blood.

Therefore, fever is a dangerous signal that a liver abscess may harm the eyes, and endophthalmitis may also occur in some patients without fever. It shows that bacteria can infect eye tissue through bacteremia without fever. Of the 19 patients in our study, 13 (68.4\%) had diabetes, which was roughly consistent with previous studies. The incidence of endophthalmitis caused 
by a liver abscess in patients with diabetes is 3.6-11.0 times higher than that in normal people ${ }^{[5]}$. Because diabetes can cause microcirculation disturbance, reduce vascular stability, increase vascular permeability, destroy the blood-retinal barrier, and create conditions for pathogenic bacteria to invade the eye ${ }^{[6]}$.

We compared the visual outcome of endophthalmitis caused by liver abscess and exogenous endophthalmitis in our hospital. It is suggested that the prognosis of endophthalmitis caused by liver abscess is worse than that of exogenous endophthalmitis. We think there are three reasons for this phenomenon.

First, the time interval between the infection of the eye and going to the ophthalmology for treatment for the first time is different. Most of the patients with exogenous endophthalmitis are primary lesions on the eyes, and the patients are easy to detect in the early stage because the attention of the patients is focused on the eyes and the compliance of the patients is good. Patients with endophthalmitis caused by liver abscess are accompanied by systemic diseases, and some patients have general discomfort during the onset of the disease, which diverts the patient's attention, and the focus of the patient's attention may be on the systemic condition while ignoring the eye symptoms.

Five of our patients did not first go to the ophthalmology department for treatment. The average duration of ophthalmic symptoms of patients who go to non-ophthalmology for diagnosis and treatment for the first time was $12.2 \pm 3.58$ days, which was significantly longer than that of $5.71 \pm 1.25$ days go to ophthalmology for the first time. The duration of ophthalmic symptoms before ophthalmology treatment is significantly related to the first diagnosis department. The patients go to nonophthalmology for diagnosis and treatment for the first time will delay the patient's condition and delay the early diagnosis of endophthalmitis. Therefore, departments related to systemic diseases that may cause endogenous endophthalmitis should strengthen doctors' understanding of endophthalmitis, pay attention to patients' eye symptoms, and inquire about eye performance as a routine consultation of the disease.

Second, the difference in virulence of pathogenic bacteria leads to a great difference in prognosis. Most of the bacteria causing exogenous endophthalmitis are less virulent bacteria such as staphylococcus epidermidis, $\beta$-streptococcus, and staphylococcus aureus. While the main pathogen of endogenous endophthalmitis caused by liver abscess is KP. In our study, 7 eyes out of 21 eyes showed positive results of vitreous fluid bacterial culture, all of which were Klebsiella pneumonia, with a positive rate of $33.3 \%$. Drug sensitivity tests showed that KP was sensitive to antibiotics except for ampicillin, which was consistent with the results of pathogens and drug resistance reported in previous experiments.

The high virulence of KP is mainly due to the irreversible damage of retinal photoreceptor cells within 48 hours after infecting the intraocular environment, so it is the golden rescue time for endophthalmitis caused by liver abscess within 48 hours after the onset of ocular symptoms. The final visual acuity of 7 eyes with positive results of microbial culture was improved by$0.0003 \pm 0.0005$, and the average visual acuity of 14 eyes with negative results was improved by $0.098 \pm 0.134$. It can be seen that the toxicity of KP will have a serious impact on visual function, if the bacteria and their toxins can not be cleaned up in the early stage, it will have a devastating effect on visual function. Therefore, the early detection and early treatment of the disease is particularly important, especially within 48 hours after the occurrence of eye discomfort. However, bacteria invade the eye at an early stage, the patient may not have any eye symptoms, and when the patient has eye symptoms, it indicates that the infection has developed to a serious extent, so the time left for ophthalmologists to save visual function will be more urgent.

Third, the accumulation sites of pathogenic bacteria and pus are different, and the pathogenic bacteria of exogenous endophthalmitis are mostly located in the anterior chamber and vitreous cavity. The pathogenic bacteria of endophthalmitis caused by liver abscess spread into the eye through the blood. In addition to the anterior chamber and vitreous cavity, a large number of bacteria accumulate under the retina, and it is more difficult to deal with subretinal bacteria and pus. The blood-eye barrier and the physical barrier of the retina limit the effect of systemic or vitreous injection on the subretinal lesions, and the failure to completely remove the subretinal lesions will lead to repeated attacks of the disease, so patients treated with IVI may need multiple injections, and the prognosis is poor. Of the 11 eyes who underwent vitrectomy, subretinal empyema was found in 6 eyes. Thorough removal of subretinal pus during the operation is a key factor affecting the prognosis of the affected eyes. For patients with endophthalmitis caused by a liver abscess, vitrectomy is of great significance to improve the prognosis, and 
to avoid the pain caused by repeated vitreous injection after the operation. The advantage of vitrectomy over simple vitreous injection is that it can quickly clean up the pathogenic bacteria in the vitreous cavity, clean up the subretinal pus and pathogenic bacteria that are difficult to be improved by conventional drug treatment, and improve the intraocular environment in time, create conditions for the recovery of retinal function.

Among the patients we treated, 3 eyes of 9 eyes treated with simple vitreous injection were treated with evisceration because the inflammation could not be controlled, so the inflammation control rate of IVI combined with systemic antibiotics was low for some pathogenic bacteria hidden in the subretinal lesions, and it was more likely that the subretinal lesions could not be cleared and the inflammation would eventually develop to panophthalmitis. In 12 eyes treated by vitrectomy, the evisceration of ocular contents was performed in 1 eye with panophthalmitis caused by recurrent inflammation. The patient with recurrent endophthalmitis after vitrectomy is transferred to hepatobiliary surgery after eye condition stable to continue treatment of liver abscess, the patient with unstable liver abscess and discharged from hospital, and systemic antibiotics are not regularly used outside the hospital, resulting in recurrent infection caused by a liver abscess. Therefore, different from the treatment of exogenous endophthalmitis only focusing on the eye condition, endophthalmitis caused by liver abscess must be actively treated based on the treatment of eye diseases. The unliquefied liver abscess is given sufficient antibiotics, and the liquefied liver abscess should be given corresponding surgical treatment actively, which is of great significance to prevent the recurrence of endophthalmitis caused by a liver abscess.

To sum up, we should strengthen education for patients with liver abscess and diabetes, pay attention to the symptoms of eye discomfort, especially teach patients to alternately cover the eye and monocular vision every day when they have symptoms of fever, to detect the loss of monocular vision which is not easy to detect in the early stage. Also, the publicity and education to other fraternal departments are of great significance. While treating systemic diseases, we should pay attention to the main complaints of patients' eye discomfort, and shorten the interval for patients to receive treatment in ophthalmology, to achieve the purpose of early detection and early treatment. The pathogenic characteristics of Klebsiella pneumonia indicate that the early detection and early intervention of endophthalmitis caused by liver abscess are of great significance to improve the prognosis. Most of the endophthalmitis caused by liver abscess have subretinal abscess lesions, and the treatment of subretinal lesions is the key to successful treatment, so vitrectomy has a better prognosis than vitreous injection alone.

\section{Declarations}

Acknowledgments

Funding This study has not any financial support.

Compliance with ethical standards.

Conflict of interest They authors declare that they have no conflict of interest.

Ethical approval All procedures performed in studies involving human participants were in accordance with the ethical standards of the institutional ethical committee and with the 1964 Helsinki Declaration and its later amendments or comparable ethical standards.

Informed consent Informed consent was obtained from all individual participants included in the study.

\section{References}

1. Fan Yuanyuan \& Wei Wenbin. (2018). New progress of endogenous endophthalmitis. International Ophthalmology Survey, $42(5), 329$

2. Yonekawa, Y., Chan, R. P., Reddy, A. K., Pieroni, C. G., Lee, T. C., \& Lee, S. (2011). Early intravitreal treatment of endogenous bacterial endophthalmitis. Clinical \& Experimental Ophthalmology. 
3. Chen, Y. J., Kuo, H. K., Wu, P. C., Kuo, M. L., Tsai, H. H., Liu, C. C., \& Chen, C. H. (2004). A 10-YEAR COMPARISON OF ENDOGENOUS ENDOPHTHALMITIS OUTCOMES: AN EAST ASIAN EXPERIENCE WITH KLEBSIELLA PNEUMONIAE INFECTION. Retina, 24.

4. Ang, P. K., Lee, H. M., Eong, K. G. A., Yap, E. Y., \& Lim, T. H. (2000). Endogenous Klebsiella endophthalmitis. Eye, 14(6), 855860.

5. R, Moore, D, et al. Community-acquired Klebsiella pneumoniae liver abscess: an emerging infection in Ireland and Europe[J]. Infection, 2013.

6. Coburn, P. S., Wiskur, B. J., Christy, E., \& Callegan, M. C. (2012). The Diabetic Ocular Environment Facilitates the Development of Endogenous Bacterial Endophthalmitis. Investigative Ophthalmology \& Visual Science, 53(12). 